\title{
ANALYSIS OF PECULIARITIES OF EPILEPTIC SEIZURES AND STRUCTURAL DAMAGES OF BRAIN IN PATIENTS WITH ISCHEMIC STROKE
}

\author{
Marianna Mushehian'1, Tetyana Litovchenko \\ ${ }^{1}$ Department of neurology and child neurology, Kharkiv Medical Academy of Postgraduate Education, Kharkiv, Ukraine \\ MIS1762020@gmail.com \\ ORCID: http://orcid.org/0000-0001-6830-2302 \\ ${ }^{2}$ Department of neurology and child neurology, Kharkiv Medical Academy of Postgraduate Education, Kharkiv, Ukraine \\ t.litovchenko@yahoo.com \\ ORCID: http://orcid.org/0000-0002-4647-8507
}

ARTICLE INFO

ABSTRACT

Article history:

Received date 25.09.2020

Accepted date 20.10.2020

Published date 30.10 .2020

Section:

Practical medicine

DOI

10.21303/2313-8416.2020.001454

KEYWORDS

epilepsy

ischemic stroke

acute cerebrovascular disease

diagnosis

structural damages

computed tomography

magnetic resonance imaging

1. Introduction

\section{1. The object of research}

The object of research is epilepsy on the background of ischemic stroke.

\section{2. Problem description}

According to the clinical standard regulated by the International Antiepileptic League (ILAE), epilepsy is diagnosed on the basis of a set of parameters, including clinical symptoms, history, electroencephalography and imaging methods of brain examination [1,2].

Unlike early post-stroke seizures, which most often occur during a patient's stay in the hospital, late seizures are more difficult to diagnose because their symptoms are often ignored or hidden in patients with severe neurological deficits after stroke. Diagnosis is facilitated if other people were present at the time of the attack or the patient witnessed a typical clinical picture characterized by focal or generalized seizures and impaired consciousness. However, often patients may not have any focal motor or sensory signs, but only slightly altered behaviour and mental status [3]. 
In some cases, late seizures are only a periodic deviation of the eyes, a slight twitching of the face or a focal change in sensitivity $[4,5]$.

Thus, the leading aspects of the clinical diagnosis of convulsive epileptic seizures, in particular, in cerebrovascular diseases, are the differentiation of epileptic seizures. An urgent problem is the diagnosis of late seizures, which develop after discharge from the hospital due to masking on the background of neurological deficits and insufficient use of objective diagnosis of epilepsy in such patients.

Neuroimaging methods are widely used to diagnose acute and chronic cerebrovascular diseases. Computed tomography and magnetic resonance imaging are important to rule out intracranial hemorrhage and detect early signs of ischemic stroke, such as large hypodense foci, significant edema or furrows absence in cerebral cortex [6].

Visualization of cerebral blood flow, achieved by contrast use, allows to establish the site of occlusion or stenosis of large vessels of the brain - computed tomography (CT) angiography, as well as to detect vascular pathologies such as atherosclerosis, aneurysm, dissection of carotid and vertebral arteries, fibromuscular dysplasia, venous thrombosis and vasculitis - magnetic resonance imaging (MRI) angiography $[6,7]$. However, none of the above techniques has an evident prognostic value in development of seizures and epilepsy after stroke.

The most common finding in patients with post-stroke seizures, which allows to differentiate the epileptic focus from the area of ischemia, is focal or diffuse hypo- or hyperperfusion of the cortex (increase in $\mathrm{CBF}$ and $\mathrm{CBV}$ ) in the absence of pathological vascular patterns (occlusion or stenosis) and basal ganglia involvement $[8,9]$. The perfusion of the epileptogenic focus varies depending on the time of the study: in the ictal phase there is a typical increase in $\mathrm{CBF}$ (hyperperfusion) simultaneously with limited diffusion, and in the postictal phase there is hypoperfusion of the cortex $[10,11]$. Therefore, in patients with acute epileptic seizures, regional hyperperfusion on perfusion CT may indicate ongoing or recently finished status epilepticus, whereas hypoperfusion may be the result of a postictal condition or acute ischemic stroke [12]. Performing perfusion MRI in patients with status epilepticus also establishes the foci of hyperperfusion in the temporal lobe of the brain cortex [13]. For patients with contraindications to the introduction of contrast, a non-invasive technique of arterial spin labelling (ASL) MRI perfusion can be used to identify foci of hypoperfusion in the postictal phase in patients with convulsions [14].

Diffusion-weighted MRI is the "gold standard" for the diagnosis of ischemic stroke $[15,16]$. They are reversible brain lesions that occur during or immediately after a seizure (often associated with status epilepticus) and are topographically related to the epileptic focus and ipsilateral thalamus. These lesions are hyperintense on T2 MRI and on DWI-ADC maps (involving the brain cortex and ipsilateral thalamus). The subcortical brain white matter usually has signs of vasogenic or cytotoxic edema $[17,18]$. Multiple signal changes may be associated with prolonged and intermittent seizures in patients with status epilepticus [19].

However, despite numerous studies of the clinical phenomenology of epilepsy, the features of the clinical condition, specific data on the association of structural damages of the brain with the development of epileptic seizures on the background of ischemic stroke in the scientific literature is still insufficiently covered.

\section{3. Suggested solution to the problem}

The described problem can be solved with the following hypothesis.

To improve the diagnosis of epilepsy on the background of cerebrovascular diseases it is essential to establish the clinical features of epileptic seizures in patients with ischemic stroke.

\section{Material and methods}

\section{1. Clinical procedures}

A cross-section randomized cohort comparative study with retrospective and prospective phases was performed.

The total number of study participants -60 people of both sexes aged 65.0 [57.0; 74.0] years, who were treated in the Department of Vascular Pathology of the Brain of the Kharkiv Clinical Hospital No. 1 on the railway transport of "Ukrzaliznytsia" in 2008-2019, of which: 
-30 people aged $70.5[62.0 ; 78.0]$ years with ischemic stroke in combination with epilepsy as the main group (group 1a);

-30 patients aged $69.5[57.0 ; 76.0]$ years with ischemic stroke without epileptic seizures as a comparison group (group 1b).

In almost all the cases the patients of group 1a developed the seizures within 24 hours after a stroke onset, with the exception of one case in which it happened on $6^{\text {th }}$ day.

According to the frequency indicators of sex, the studied groups were compared.

In terms of ethics and bioethics, the study was conducted in accordance with current legislation in the world and in Ukraine and sectoral regulatory documents, in particular: "Ethical principles for medical research involving human subjects" (adopted by the 18th World Medical Association General Assembly, Helsinki, Finland, June 1964); principles of the International Conference on Harmonization Good Clinical Practice (ICH-GCP) etc. The study was performed with minimal psychological loss on the part of patients. All participants were fully informed about the purpose and objectives, research methods, medications and their mode of use, the potential benefits and risks, as well as possible discomfort during diagnosis and treatment, and agreed to participate in the study. The study did not use any measures or tools that went beyond standard approaches to the diagnosis and treatment of the study pathology and (or) associated with additional risks or costs for the study participant. The study was approved by the Comission in Bioethics of Kharkiv Medical Academy of Post-Graduate Education (protocol no. 9, October, 15 ${ }^{\text {th }}, 2018$ ).

\section{2. Materials and methods}

Magnetic resonance imaging of the brain was performed according to standard methods on a high-field MRI 1.5 Tesla (Siemens, Germany) to characterize brain damage. The following localization options were differentiated: right or left hemisphere; temporal, occipital, frontal, temporal lobes of the brain; subcortical ganglia, subcortex, cortical ganglia. Also registered: the presence of dilatation of the ventricles of the brain, diffuse atrophic changes in the cortical departments; expansion of the subarachnoid space. Fazekas scale was used to assess the degree of damage to the white matter of the brain in the conditions of its ischemia, gradation of changes in the periventricular white matter: 0 - no changes; 1 - "caps" are available or thin lines; 2 - there is a moderate "halo"; 3 - uneven periventricular zones of leukoareosis are established.

Logical and statistical analysis was performed by nonparametric methods. Thus, the central regularity of the studied parameters in the assessment of the group of subjects was expressed using the median (Me), and the variability - the lower, 25 percent, quartile (LQ) and upper, 75 percent quartile (UQ), for brevity, expressing the description in: Me [LQ; UQ]. Qualitative, binary, ordinal indicators were described in frequency values - absolute and relative (percentage) with SD guidance. The groups were compared in pairs using Fisher's angular transformation, the value of the empirical angle and the corresponding p-level were given; more than two groups - with construction of conjugacy tables and application of the method of maximum likelihood of Pearson's chi-square $\left(\chi^{2}\right)$ criterion. In all types of statistical analysis, trends at the p-level less than 0.05 were considered statistically significant

\section{Results}

The characteristics of epileptic seizures in patients with acute cerebrovascular pathology was performed (Table 1).

\section{Table 1}

Characteristics of epileptic seizures in patients with acute cerebrovascular pathology

\begin{tabular}{|c|c|c|c|}
\hline \multirow{2}{*}{ Presence of epileptic attacks } & \multicolumn{3}{|c|}{ Group 1a } \\
\hline & Abs. & $\%$ & SD \\
\hline - focal motor & 4 & 13.3 & 12.4 \\
\hline - focal with impaired awareness of seizures and transformation to bilateral & 3 & 10.0 & 9.5 \\
\hline - generalized & 20 & 66.7 & 38.5 \\
\hline
\end{tabular}


Further analysis of the structure of epileptic seizures was performed, taking into account the age of patients, localization of vascular lesions and areas of the brain, type of stroke, etc.

A higher frequency of generalized single variants of seizures in patients over 60 years of age (maximum at 61-70 years, at descending - 71-80 years, over 80 years) has been detected (Fig. 1).

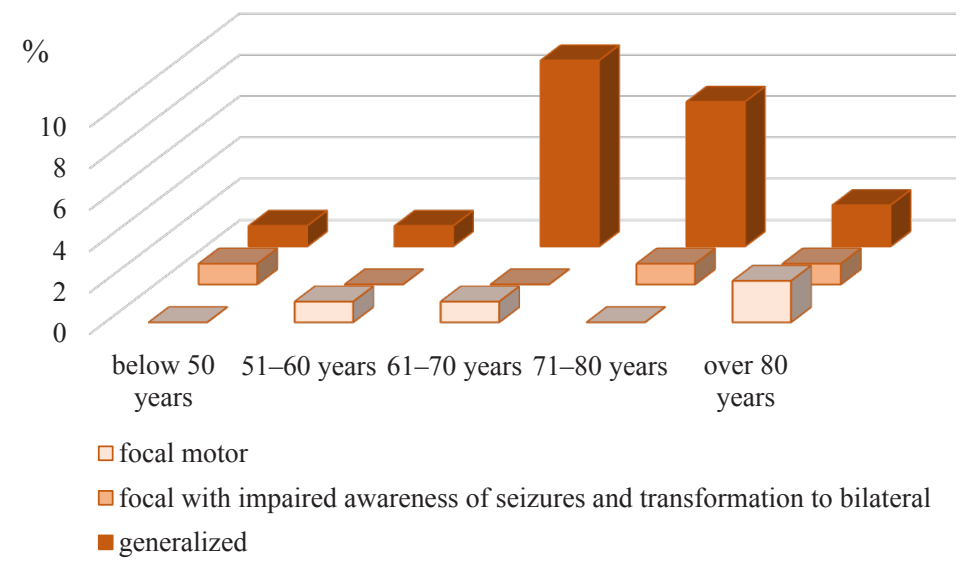

Fig. 1. Age characteristics of epileptic seizures variants in patients of 1a group with acute cerebrovascular pathology

There was an interest to distinguish the rates of epileptic relapses (with type of seizures) in both groups. So, in la group in 9 (30.0 \%) patients focal seizures were detected at 24 [21; 26] days, against $2(6.7 \%)$ patients with generalized ones on $20^{\text {th }}$ and 23 th days $(\mathrm{p}<0.01)$; in $1 \mathrm{~b}$ group only in $1(3.4 \%)$ person the generalized seizures were revealed on $30^{\text {th }}$ day.

Magnetic resonance imaging allowed to characterize the localization of brain damage (Table 2).

Table 2

Frequency of brain damage localization in patients with acute cerebrovascular disease

\begin{tabular}{|c|c|c|c|c|c|c|}
\hline \multirow{2}{*}{ Brain lesions location } & \multicolumn{3}{|c|}{$\begin{array}{l}\text { Group 1a, } \\
\mathbf{n}=\mathbf{3 0}\end{array}$} & \multicolumn{3}{|c|}{$\begin{array}{l}\text { Group 1b, } \\
\mathbf{n}=\mathbf{3 0}\end{array}$} \\
\hline & Abs. & $\%$ & SD & Abs. & $\%$ & SD \\
\hline Right hemisphere & 18 & 60.0 & 37.9 & 14 & 46.7 & 34.1 \\
\hline Left hemisphere & 13 & 43.3 & 32.6 & 18 & 60.0 & 37.9 \\
\hline Parietal part & 18 & 60.0 & 37.9 & 23 & 76.7 & 37.0 \\
\hline Occipital lobe & 5 & 16.7 & 15.2 & 6 & 20.0 & 17.9 \\
\hline Frontal lobe & 15 & 50.0 & 35.4 & 10 & 33.3 & 27.2 \\
\hline Temporal part & 6 & 20.0 & 17.9 & 6 & 20.0 & 17.9 \\
\hline Subcortical ganglia & 23 & 76.7 & 37.0 & 18 & 60.0 & 37.9 \\
\hline Subcortex & 17 & 56.7 & 37.3 & 12 & 40.0 & 31.0 \\
\hline Cortical ganglia & 19 & 63.3 & 38.4 & 16 & 53.3 & 36.4 \\
\hline Ventricular dilation & 25 & 83.3 & 34.0 & 21 & 70.0 & 38.3 \\
\hline $\begin{array}{l}\text { Diffuse-atrophic changes in } \\
\text { the cortical departments }\end{array}$ & 13 & 43.3 & 32.6 & 11 & 36.7 & 29.2 \\
\hline Expansion of the subarachnoid space & 28 & 93.3 & 24.1 & 30 & 100.0 & 0.0 \\
\hline
\end{tabular}


The rank distribution of the frequency of localization of brain damage (my MRI and CT) in patients with epileptic seizures after ischemic stroke (group 1a) was as follows (in descending order): expansion of the subarachnoid space (93.3 $\pm 24.1 \%)$, ventricular dilation $(83.3 \pm 34.0 \%)$, subcortical ganglia $(76.7 \pm 37.0 \%)$, right hemisphere or temporal lobe $(60.0 \pm 37.9 \%)$, subcortex $(56.7 \pm 37.3 \%)$, frontal lobe $(50.0 \pm 35.4 \%)$, the rest did not exceed $50 \%$.

The severity of damage to the white matter of the brain under conditions of its ischemia by the Fazekas scale was evaluated (Table 3).

Table 3

Frequency of white matter of the brain in patients with acute cerebrovascular disease

\begin{tabular}{ccccccc}
\hline & \multicolumn{3}{c}{$\begin{array}{c}\text { Group 1a, } \\
\mathbf{n = 3 0}\end{array}$} & & \multicolumn{3}{c}{$\begin{array}{c}\text { Group 1b, } \\
\mathbf{n = 3 0}\end{array}$} \\
\cline { 2 - 7 } Points quantity (by Fazekas scale) & & $\mathbf{0}$ & SD & Abs. & $\mathbf{\%}$ & SD \\
\hline A points & 19 & 63.3 & 38.4 & 20 & 66.7 & 38.5 \\
1 point & 9 & 30.0 & 25.1 & 8 & 26.7 & 22.8 \\
2 points & 2 & 6.7 & 6.4 & 2 & 6.7 & 6.4 \\
3 points & 0 & 0.0 & 0.0 & 0 & 0.0 & 0.0
\end{tabular}

The frequency of brain lesions localization was performed taking into account the assessment of the degree of white matter damage in the brain in conditions of its ischemia by the Fazekas scale among patients with ischemic stroke who developed epileptic seizures (Table 4) and did not develop them (Table 5).

Table 4

Frequency of brain damage localization in patients with ischemic stroke and epileptic seizures based on the Fazekas score

\begin{tabular}{|c|c|c|c|c|c|c|c|c|c|}
\hline \multirow{2}{*}{ Location of brain lesions } & \multicolumn{3}{|c|}{0 points by Fazekas, n=19 } & \multicolumn{3}{|c|}{1 points by Fazekas, $n=9$} & \multicolumn{3}{|c|}{2 points by Fazekas, $n=2$} \\
\hline & Abs. & $\%$ & SD & Abs. & $\%$ & SD & Abs. & $\%$ & SD \\
\hline Right hemisphere & 8 & 42.1 & 32.0 & 8 & 88.9 & 29.6 & 2 & 100.0 & 0.0 \\
\hline Left hemisphere & 11 & 57.9 & 37.6 & 2 & 22.2 & 19.6 & 0 & 0.0 & 0.0 \\
\hline Parietal part & 10 & 52.6 & 36.2 & 6 & 66.7 & 38.5 & 2 & 100.0 & 0.0 \\
\hline Occipital lobe & 4 & 21.1 & 18.7 & 0 & 0.0 & 0.0 & 1 & 50.0 & 35.4 \\
\hline Frontal lobe & 8 & 42.1 & 32.0 & 7 & 77.8 & 36.7 & 0 & 0.0 & 0.0 \\
\hline Temporal part & 4 & 21.1 & 18.7 & 2 & 22.2 & 19.6 & 0 & 0.0 & 0.0 \\
\hline Subcortical ganglia & 14 & 73.7 & 37.8 & 7 & 77.8 & 36.7 & 2 & 100.0 & 0.0 \\
\hline Subcortex & 10 & 52.6 & 36.2 & 6 & 66.7 & 38.5 & 1 & 50.0 & 35.4 \\
\hline Cortical ganglia & 11 & 57.9 & 37.6 & 6 & 66.7 & 38.5 & 2 & 100.0 & 0.0 \\
\hline Ventricular dilation & 14 & 73.7 & 37.8 & 9 & 100.0 & 0.0 & 2 & 100.0 & 0.0 \\
\hline $\begin{array}{l}\text { Diffuse-atrophic changes in the cortical } \\
\text { departments }\end{array}$ & 8 & 42.1 & 32.0 & 4 & 44.4 & 33.1 & 1 & 50.0 & 35.4 \\
\hline Expansion of the subarachnoid space & 17 & 89.5 & 29.0 & 9 & 100.0 & 0.0 & 2 & 100.0 & 0.0 \\
\hline
\end{tabular}


Table 5

Frequency of brain damage localization in patients with ischemic stroke without epileptic seizures based on the Fazekas score

\begin{tabular}{|c|c|c|c|c|c|c|c|c|c|}
\hline \multirow{2}{*}{ Location of brain lesions } & \multicolumn{3}{|c|}{0 points by Fazekas, $n=19$} & \multicolumn{3}{|c|}{1 points by Fazekas, $n=9$} & \multicolumn{3}{|c|}{2 points by Fazekas, $n=2$} \\
\hline & Abs. & $\%$ & SD & Abs. & $\%$ & SD & Abs. & $\%$ & SD \\
\hline Right hemisphere & 9 & 45.0 & 33.4 & 4 & 50.0 & 35.4 & 1 & 50.0 & 35.4 \\
\hline Left hemisphere & 12 & 60.0 & 37.9 & 4 & 50.0 & 35.4 & 2 & 100.0 & 0.0 \\
\hline Parietal part & 16 & 80.0 & 35.8 & 5 & 62.5 & 38.3 & 2 & 100.0 & 0.0 \\
\hline Occipital lobe & 3 & 15.0 & 13.8 & 4 & 50.0 & 35.4 & 0 & 0.0 & 0.0 \\
\hline Frontal lobe & 5 & 25.0 & 21.7 & 4 & 50.0 & 35.4 & 1 & 50.0 & 35.4 \\
\hline Temporal part & 2 & 10.0 & 9.5 & 3 & 37.5 & 29.6 & 1 & 50.0 & 35.4 \\
\hline Subcortical ganglia & 11 & 55.0 & 36.9 & 5 & 62.5 & 38.3 & 2 & 100.0 & 0.0 \\
\hline Subcortex & 7 & 35.0 & 28.2 & 3 & 37.5 & 29.6 & 2 & 100.0 & 0.0 \\
\hline Cortical ganglia & 9 & 45.0 & 33.4 & 5 & 62.5 & 38.3 & 2 & 100.0 & 0.0 \\
\hline Ventricular dilation & 12 & 60.0 & 37.9 & 7 & 87.5 & 30.9 & 2 & 100.0 & 0.0 \\
\hline $\begin{array}{l}\text { Diffuse-atrophic changes in the cortical } \\
\text { departments }\end{array}$ & 5 & 25.0 & 21.7 & 4 & 50.0 & 35.4 & 2 & 100.0 & 0.0 \\
\hline Expansion of the subarachnoid space & 20 & 100.0 & 0.0 & 8 & 100.0 & 0.0 & 2 & 100.0 & 0.0 \\
\hline
\end{tabular}

\section{Discussion}

Thus, the structured characteristics of epileptic seizures in patients with acute cerebrovascular pathology allowed to establish their features taking into account their variants, age of patients etc. The evaluation of structural disorders of the brain in patients with ischemic stroke with the development of epileptic seizures may be a means of improving the diagnosis of epilepsy on the background of cerebrovascular diseases.

We believe that the clinical variants of seizures and peculiarities of brain damage detected by MRI and CT may have a predictive value. Patients having acute and chronic cerebrovascular pathology may have different clinical picture of seizures, and the analysis of literature allows to establish similar tendencies.

In the J. Conrad et al. (2013) study [19], the frequency of suicide attacks for cerebrovascular events (stroke, transient ischemic attack, internal cranial venous thrombosis) was $11.6 \%$ (49 patients). The majority of attacks were bully generalized (57.1\%), and focal attacks were suspected in $40.8 \%$, of which $55.0 \%$ were with saved consciousness, and in $45.0 \%$ of cases, there were disturbances of it. At the same time, among patients with an early seizures, the frequency of generalized attacks was $60.9 \%$, focal attacks $-39.1 \%$. Likewise, $16.7 \%$ of cases had an epileptic status, which is more characteristic for a late seizures onset, and $6.3 \%$ had a Todd paralysis, which is more often developed in patients with early seizures [19].

F. Brigo et al. (2019) [20] have studied the patients with early seizures, and they revealed that after the first 3 days of the stroke, the seizures developed in $75.9 \%$ of the patients. The majority of them were focal with saved consciousness $(46.7 \%)$ or generalized $(43.3 \%)$. Focal attacks with disturbed consciousness were detected in $6.7 \%$ of patients, and an epileptic status and non-motor attacks were not detected in any of them. However, the information consistency is unclear because of no EEG in the patients with a stroke [20]. While in the recent systematic survey by Xu M. Y. [3] which included 37 studies and 36 thousand participants it was shown that $73.6 \%$ of early seizures developed in 24 years, and $39.6 \%$ - immediately with a stroke onset. Two-thirds of the patients had seizures with a focal onset, and less than one third - a generalized. Epileptic status was in $16.3 \%$ of patients [3]. 
Most often the clinical picture of seizures corresponds to the side of the ischemia zone in the acute period of stroke, and the more time passes from the onset of an acute disturbance of brain circulation to the first seizures, the greater dissociation occurs, which probably indicates the formation of areas of epileptogenesis not associated with primary necrosis focus.

Patients with cerebrovascular diseases may have a different clinical picture of seizures, although the informativeness of clinical data alone is insufficient and must be provided by the systematic implementation of electroencephalography in all patients with stroke [3].

In brain ischemia which develops as a result of occlusion of the vessels of the vertebrobasilar basin, there may be convulsive movements [20]. It has also been reported that stroke cases associated with the basal ganglia or frontal lobe can cause hemichorea and convulsions similar to seizures [21, 22]. A special type of convulsive movement is tremor, which develops during transient ischemic attacks, as a result of secondary focal hypoperfusion of the brain due to a pronounced degree of occlusion or stenosis of the carotid artery [3].

Thus, the features of the clinical condition, specific data on the association of structural damages of the brain with the development of epileptic seizures on the background of ischemic stroke can help in the diagnosis of this pathology.

The study limitations. The amount of patients examined is the limitation of the study. More of them might improve the statistical power of the study and let us either detect more statistical tendencies or perform more detailed analysis.

The prospect of further research is to study the association of structural disorders of the brain with the development of epileptic seizures in cerebrovascular disorders.

\section{Conclusions}

1. The predominance of generalized $(66.7 \pm 38.5 \%)$ variants was found in the structure of epileptic seizures in patients with acute cerebrovascular pathology.

2. A higher frequency of generalized variants of seizures in patients over 60 years of age (maximum at 61-70 years, at descending - 71-80 years, over 80 years) has been revealed.

3. Characterization of structural disorders of the brain in patients with ischemic stroke with the development of epileptic seizures may be a means of improving the diagnosis of epilepsy on the background of cerebrovascular disease.

4. The descending distribution of localization frequency of brain lesions (detected by MRI and CT) in patients with epileptic seizures after ischemic stroke is as follows: dilation of the subarachnoid space $(93.3 \pm 24.1 \%)$, dilation of the brain ventricles $(83.3 \pm 34.0 \%)$, subcortical ganglia $(76.7 \pm 37.0 \%)$, right hemisphere or temporal lobe $(60.0 \pm 37.9 \%)$, subcortex $(56.7 \pm 37.3 \%)$, frontal lobe $(50.0 \pm 35.4 \%)$, left hemisphere or diffuse-atrophic changes in the cortical region $(43.3 \pm 32.6 \%)$, temporal lobe $(20.0 \pm 17.9 \%)$, occipital lobe $(16.7 \pm 15.2 \%)$.

5. The evaluation of the brain's structural disorders in patients with ischemic stroke with the development of epileptic seizures may be a means of improving the diagnosis of epilepsy on the background of cerebrovascular disease.

\section{Conflict of interests}

The authors declare that they have no conflicts of interest.

\section{Acknowledgments}

Special thanks to the colleagues from:

- Kharkiv Clinical Hospital No.1 on the railway transport of "Ukrzaliznytsia", the Department of Vascular Pathology of the Brain - for help in data collection;

- Kharkiv Medical Academy of Postgraduate Education, the Department of Neurology and Child Neurology - for methodological supervision.

\section{References}

[1] Scheffer, I. E., Berkovic, S., Capovilla, G., Connolly, M. B., French, J., Guilhoto, L. et. al. (2017). ILAE classification of the epilepsies: Position paper of the ILAE Commission for Classification and Terminology. Epilepsia, 58 (4), $512-521$. doi: http://oi.org/10.1111/epi.13709 
[2] Trinka, E., Cock, H., Hesdorffer, D., Rossetti, A. O., Scheffer, I. E., Shinnar, S. et. al. (2015). A definition and classification of status epilepticus - Report of the ILAE Task Force on Classification of Status Epilepticus. Epilepsia, 56 (10), $1515-1523$. doi: http://doi.org/10.1111/epi.13121

[3] Xu, M. Y. (2018). Poststroke seizure: optimising its management. Stroke and Vascular Neurology, 4 (1), $48-56$. doi: http://doi.org/10.1136/svn-2018-000175

[4] Miyaji, Y., Kawabata, Y., Joki, H., Seki, S., Mori, K., Kamide, T. et. al. (2017). Late Seizures after Stroke in Clinical Practice: The Prevalence of Non-convulsive Seizures. Internal Medicine, 56 (6), 627-630. doi: http://doi.org/10.2169/internalmedicine.56.7162

[5] Assadeck, H., Toudou-Daouda, M., Mamadou, Z., Moussa-Konate, M., Hassane-Djibo, F., Douma-Maiga, D. (2019). Clinical and Etiological Characteristics of Epilepsy in the Elderly: A Hospital-Based Study from a Tertiary Care Referral Center of Niamey, Niger. Journal of Neurosciences in Rural Practice, 10 (4), 571-575. doi: http://doi.org/10.1055/s-0039-1700308

[6] Birenbaum, D., Bancroft, L. W., Felsberg, G. J. (2011). Imaging in Acute Stroke. Western Journal of Emergency Medicine, $12(1), 67-76$.

[7] Guerrero, W. R., Golubczyk, D., Walczak, P. (2019). Thrombus Imaging in Acute Stroke. Stroke, 50 (8), 1948-1949. doi: http:// doi.org/10.1161/strokeaha.119.025866

[8] Kubiak-Balcerewicz, K., Fiszer, U., Nagańska, E., Siemianowski, C., Sobieszek, A., Witak-Grzybowska, A., Kosińska-Szot, A. (2017). Differentiating Stroke and Seizure in Acute Setting - Perfusion Computed Tomography? Journal of Stroke and Cerebrovascular Diseases, 26 (6), 1321-1327. doi: http://doi.org/10.1016/j.jstrokecerebrovasdis.2017.02.002

[9] López Ruiz, R., Quintas, S., Largo, P., de Toledo, M., Carreras, M. T., Gago-Veiga, A. et. al. (2019). Usefulness of multiparametric computerised tomography findings in the differential diagnosis of stroke mimics of epileptic origin: A preliminary study. Neurología, 34 (2), 73-79. doi: http://doi.org/10.1016/j.nrleng.2018.11.001

[10] Koome, M., Churilov, L., Chen, Z., Chen, Z., Naylor, J., Thevathasan, A. et. al. (2016). Computed tomography perfusion as a diagnostic tool for seizures after ischemic stroke. Neuroradiology, 58 (6), 577-584. doi: http://doi.org/10.1007/s00234-016$1670-5$

[11] Austein, F., Huhndorf, M., Meyne, J., Laufs, H., Jansen, O., Lindner, T. (2017). Advanced CT for diagnosis of seizure-related stroke mimics. European Radiology, 28 (5), 1791-1800. doi: http://doi.org/10.1007/s00330-017-5174-4

[12] Katramados, A. M., Hacein-Bey, L., Varelas, P. N. (2018). What to Look for on Post-stroke Neuroimaging. Neuroimaging Clinics of North America, 28 (4), 649-662. doi: http://doi.org/10.1016/j.nic.2018.06.007

[13] Chen, G., Lei, D., Ren, J., Zuo, P., Suo, X., Wang, D. J. J. et. al. (2016). Patterns of postictal cerebral perfusion in idiopathic generalized epilepsy: a multi-delay multi-parametric arterial spin labelling perfusion MRI study. Scientific Reports, 6 (1). doi: http://doi.org/10.1038/srep28867

[14] Gaxiola-Valdez, I., Singh, S., Perera, T., Sandy, S., Li, E., Federico, P. (2017). Seizure onset zone localization using postictal hypoperfusion detected by arterial spin labelling MRI. Brain, 140 (11), 2895-2911. doi: http://doi.org/10.1093/brain/awx241

[15] Liang, J., Gao, P., Lin, Y., Song, L., Qin, H., Sui, B. (2018). Susceptibility-weighted imaging in post-treatment evaluation in the early stage in patients with acute ischemic stroke. Journal of International Medical Research, 47 (1), $196-205$. doi: http://doi.org/10.1177/0300060518799019

[16] Leigh, R., Krakauer, J. W. (2014). MRI-guided selection of patients for treatment of acute ischemic stroke. Current Opinion in Neurology, 27 (4), 425-433. doi: http://doi.org/10.1097/wco.0000000000000110

[17] Cartagena, A. M., Young, G. B., Lee, D. H., Mirsattari, S. M. (2014). Reversible and irreversible cranial MRI findings associated with status epilepticus. Epilepsy \& Behavior, 33, 24-30. doi: http://doi.org/10.1016/j.yebeh.2014.02.003

[18] Ohe, Y., Hayashi, T., Deguchi, I., Fukuoka, T., Horiuchi, Y., Maruyama, H. et. al. (2014). MRI abnormality of the pulvinar in patients with status epilepticus. Journal of Neuroradiology, 41 (4), 220-226. doi: http://doi.org/10.1016/j.neurad.2013.09.003

[19] Conrad, J., Pawlowski, M., Dogan, M., Kovac, S., Ritter, M. A., Evers, S. (2013). Seizures after cerebrovascular events: Risk factors and clinical features. Seizure, 22 (4), 275-282. doi: http://doi.org/10.1016/j.seizure.2013.01.014

[20] Brigo, F., Schneider, M., Wagenpfeil, G., Unger, M. M., Holzhoffer, C., Walter, S. et. al. (2020). Early poststroke seizures following thrombolysis and/or thrombectomy for acute stroke: Clinical and stroke characteristics. Epilepsy \& Behavior, 104, 106353. doi: http://doi.org/10.1016/j.yebeh.2019.05.048

[21] Ghika, J., Bogousslavsky, J., van Melle, G., Regit, F. (1995). Hyperkinetic Motor Behaviors Contralateral to Hemiplegia in Acute Stroke. European Neurology, 35 (1), 27-32. doi: http://doi.org/10.1159/000117085

[22] Kim, B. S., Sila, C. (2015). Seizures in Ischemic Stroke. In. Koubeissi MZ, ed. Seizures in cerebrovascular disorders. New York: Springer Science+Business Media, 17-29. doi: http://doi.org/10.1007/978-1-4939-2559-9_2 